\title{
Using Tailored Information and Public Commitment to Improve the Environmental Quality of Farm Lands: An Example from the Netherlands
}

\author{
Anne Marike Lokhorst • Jerry van Dijk • Henk Staats • \\ Eric van Dijk • Geert de Snoo \\ Published online: 30 September 2009 \\ (C) The Author(s) 2009. This article is published with open access at Springerlink.com
}

\begin{abstract}
By adopting nature conservation practices, farmers can enhance the environmental quality and biodiversity of their land. In this exploratory study, a behavioral intervention that focused on improving Dutch farmers' nature conservation practices was developed and tested. This intervention was based on insights derived from social psychology and combined tailored information and public commitment. Participating farmers were divided in three groups: one group received tailored information only, one group received both tailored information and a public commitment manipulation, and one group served as a control. A questionnaire measuring relevant aspects of conservation was completed before and after the intervention. Results show that tailored information combined with public commitment making resulted in a stronger desire to engage in conservation, an increase in surface area of nonsubsidized natural habitat, and an increase in time farmers spent on conservation. The intervention affected both subsidized and non-subsidized conservation, but the effects were stronger for non-subsidized conservation.
\end{abstract}

Keywords Tailored information - Commitment · Farmers . Nature conservation · Intervention · The Netherlands

A. M. Lokhorst $(\bowtie) \cdot H$. Staats $\cdot$ E. van Dijk

Social and Organizational Psychology Unit, Leiden University, P.O. Box 9555, 2300 RB Leiden, The Netherlands

e-mail: ALokhorst@fsw.leidenuniv.nl

J. van Dijk

Utrecht University, Faculty of Geosciences,

P.O. Box 80115, 3508 TC Utrecht, The Netherlands

G. de Snoo

Leiden University, CML,

2333 CC Leiden, The Netherlands

\section{Introduction}

Scientists, policy makers and the general public agree that action must be undertaken to stop the rapid degradation of our natural environment. While technical solutions and environmental policies are promising, they can only be successful when accompanied by changes in human behavior (Stern and Oskamp 1987). A vast amount of research has focused on changing people's environmental attitudes and behaviors and has yielded mixed results (for reviews, see Abrahamse et al. 2005; De Young 1993; Dwyer et al. 1993). While these studies typically focus on household behaviors such as recycling (e.g., DeLeon and Fuqua 1995; Harland et al. 1999) and energy conservation (Katzev and Johnson 1983; Pallak and Cummings 1976), Gardner and Stern (2002) argue that research should target those behaviors that have the largest impact on our environment.

One approach is to distinguish environmental behaviors such as using energy-efficient lamps and lowering the thermostat in workplaces and homes in terms of their effect on the environment, and then target the behaviors that beneficially affect the environment the most. A complementary approach would be to distinguish among groups of people in terms of their influence on the environment based on their social and/or employment status. If certain groups are identified as having a significant influence on the environment, then it makes sense to target these people and their environmental behaviors specifically.

Following this line of reasoning, in the current study we focus on farmers in The Netherlands, who have a tremendous influence on the environment due to the large areas of land in agricultural use. More specifically, by adopting nature conservation practices, farmers can improve the quality of their land. This study focuses on the potential for improving these conservation practices by 
developing and testing a behavioral intervention based on the large body of social psychological research on interventions in the environmental domain. A key aspect of the current study is that it combines social psychological measures with ecological ones, making it possible to test relations between aspects of motivation and outcomes on the level of environmental quality. The authors of this article include both psychologists and ecologists.

\section{Intervention}

There is a great deal of research dedicated to developing and testing interventions aimed at changing environmental behaviors (Dwyer et al. 1993), for examples goal setting, mass media campaigns, and the distribution of rewards or token reinforcers such as coupons. Systematic reviews suggest that the most effective interventions are based on feedback, tailored information and commitment making (Abrahamse et al. 2005; Dwyer et al. 1993).

Attempts to change people's attitudes and behaviors often rely on the presentation of information. One informational technique that has often been used in social psychological research is feedback (see, for instance, Abrahamse et al. 2007; Staats et al. 2004). Administering feedback entails providing people with information about their current behavior. A distinction is made between feedback on the individual and on the group level. The latter is also described as a type of comparative feedback as it provides the opportunity to compare one's behavior with that of others. This way feedback can be successful in changing behavior because it possibly makes salient a social norm in favor of the behavior at stake (Abrahamse et al. 2007). Another informational technique is the provision of information that is tailored specifically to a person's individual needs. This technique has been used for example to provide advice to garage managers on how to reduce oil pollution of wastewater (Daamen et al. 2001) and was found effective. An important aspect of Daamen et al.'s study is that it targeted professionals instead of the more usual and general sample of consumers.

An important distinction between feedback and tailored information is that feedback is a so-called consequent strategy (informing participants about the consequences of their behavior) whereas providing tailored information is an antecedent strategy (informing participants on how to alter their future behavior effectively; see Dwyer et al. 1993). In this study we used both techniques in order to increase the effectiveness of the intervention. That is to say, we provided our participants with feedback about their current conservation behavior and its consequences combined with tailored information on how to effectively improve their conservation behavior. Throughout the article we refer to this treatment as "tailored information."
The effects of informational techniques are often limited to short periods of time (Staats et al. 2000). Also, it is assumed that interventions are more successful when they are multifaceted and consist of multiple strategies (Gardner and Stern 2002; Werner et al. 1995). Therefore in the current research we decided to further enrich our intervention package with a technique called public commitment making, in which an individual is asked to make a commitment to certain behavior(s) in the presence of other people. Commitment-making is generally seen as a promising intervention technique (Abrahamse et al. 2005; De Young 1993; Dwyer et al. 1993; Katzev and Wang 1994) and has been shown to influence, for example, recycling behavior (DeLeon and Fuqua 1995; Wang and Katzev 1990) and use of public transport rather than private vehicles (Matthies et al. 2006). Public commitment can influence behavior in a number of ways (Lokhorst et al. 2009a). First, it can change people's self-image such that the new behavior becomes a part of their self- identity. Second, it can evoke a willingness to conform to either a societal or personal norm to engage in the behavior in question. Third, it can set in motion a process generally referred to as cognitive elaboration (Petty and Cacioppo 1986), a process whereby the individual elaborates on the possible reasons to engage in the behavior and strategies to accurately perform the behavior, resulting in a strong positive attitude towards the behavior.

\section{The Current Research: Farmers and Conservation}

Many species of flora and fauna associated with farmlands have shown severe declines over the last decades (Berendse et al. 2004). Intensification of farming, as a result of mechanization, increased sizes of individual farms and the extensive use of fertilizers and agrochemicals, is seen as the main cause for this biodiversity loss in the European countryside (Benton et al. 2003). Farmers' conservation practices have been officially acknowledged by the EU Common Agricultural policy (CAP) since the early 1990s (European Commission, Directorate-General for Agriculture 2003), and, as a result, many countries have set up subsidy schemes to promote agricultural conservation practices. These schemes aim to encourage farmers to set aside part of their productive lands for the creation of semi-natural habitats (for a detailed overview of schemes, see Kleijn and Sutherland 2003). In addition, farmers can undertake non-subsidized and uncompensated conservation practices.

This study focuses on conservation practices designed to reduce emissions of agrochemicals and fertilizer into the environment, as well as the management and maintenance of semi-natural habitats such as riparian zones and hedgerows. To the best of our knowledge, no other research has yet focused on testing a social psychological intervention 
aimed at increasing beneficial environmental behaviors. Our approach, combining both tailored information and public commitment, is based on the assumption of voluntary behavior change. Both subsidized and nonsubsidized conservation are voluntary behaviors. Even though subsidized conservation is contingent on contracts and thus less flexible, farmers are still free to participate in conservation schemes or not. Also, they are free to put in as much or as little effort as they wish as long as they meet required standards. Therefore both subsidized and nonsubsidized conservation may be influenced by our intervention package. However, it could also be that the effect of our intervention is stronger in the absence of any monetary rewards. Research has shown that rewarding a behavior can cause a decline in intrinsic motivation for this behavior, a process called the "crowding out effect" (Frey 1997). Ultimately, financially rewarding conservation practices creates a dependency that is self-sustaining, costly, and therefore vulnerable. Leaving moral considerations aside, the development of interventions based on voluntary cooperation can be justified by this inherent weakness of subsidized programs. To test the full effect of our intervention and to be able to compare outcomes of nonsubsidized conservation programs with subsidized conservation programs we included measures for both.

We expected that especially the combination of tailored information and public commitment would result in stronger motivation to engage in conservation practices and more/better conservation practices. To test this, we created three experimental conditions: (1) tailored information plus public commitment, (2) tailored information only, and (3) control. This way we could test whether tailored information alone is sufficient to elicit change, or whether it should be accompanied by public commitment. A questionnaire measuring relevant aspects of both subsidized and non-subsidized conservation was completed by participants before and after our intervention. Specifically, we hypothesized that the combination of tailored information and public commitment would result in a more positive attitude towards conservation, a stronger desire to engage in conservation practices, more time spent on conservation efforts, higher quality of conservation practices, an increase in the area of (semi) natural habitat, and more biodiversity, compared to tailored information only and control conditions. In addition, we expected the tailored information only condition would produce more of these outcomes compared to the control condition.

\section{Methods}

This study lasted for one year from October 2006 to October 2007 in Zeeland, a province in the southwest of the
Netherlands. We restricted the research to farms in the marine clay district to minimize the influence of differences in soil or landscape on farm characteristics and possibilities for conservation practices. For similar reasons we restricted our study to arable farms. Generally, farmers grew a combination of wheat, potatoes, beets, and onions, often complemented with other crops, including grass seed, linseed or fruit trees. Farmers were recruited through their local agricultural organizations. These agricultural organizations generally aim to increase the ecological values of farms by jointly applying for conservation subsidies, and to increase the general public's goodwill towards farmers. Their members meet to discuss these and related issues on a regular basis, though the frequency of these meetings varies. These organizations are growing rapidly - their members own $50 \%$ of total Dutch farmland (Oerlemans et al. 2007). Since this group of farmers is becoming increasingly important we chose to focus on them specifically.

\section{Participants}

Participants were initially contacted by telephone. If they agreed to participate, they received the baseline questionnaire at home, together with a return envelope. The initial wave of data collection took place in March 2006. In total, the questionnaire was sent to 112 farmers, of which 84 farmers (94.1\% male, mean age 46.9 years) completed and returned it, a response rate of 78\% (Lokhorst et al. 2009b). Farm sizes in our sample ranged from 4.47 to 200 ha.

During the course of the study, 26 participants dropped out. Total attrition from pretest to post-test was $31 \%$. To examine the nature of attrition, a comparison was made between participants who had dropped out and those who remained in the study on treatment group, average scores of time spent on nature conservation, attitude towards nature conservation, and the basic demographics of gender, age and farm size. Since farmers are generally reluctant to provide their annual income, farm size was chosen as a proxy for socioeconomic status. None of these differences were statistically significant, suggesting that the dropout rate in this study was not selective.

\section{Study Design}

The final sample who filled out both questionnaires consisted of 58 participants $(70.2 \%$ male, mean age 49.7 years). We divided participants into three groups: one group received tailored information only, one group received tailored information plus a public commitment manipulation, and one group served as a control. In the tailored information only group $(N=18)$, participants were sent feedback reports by mail tailored around the themes 
habitat area, habitat diversity and quality of conservation. Habitat diversity and adequate habitat management in particular are seen as key drivers of biodiversity in agricultural landscapes (Benton et al. 2003; Blomqvist et al. 2006; Duelli 1997; Manhoudt et al. 2007; Weibull et al. 2003). As a source for adequate conservation options, we used a manual for agri-environmental management (Van Paassen and Schrieken 1998), published by the Dutch national organization for landscape management which is a widely accepted source of advice about agriculturalenvironmental conservation options.

Feedback reports were tailored for each farm using selfreported data on habitat area and conservation. Based on this information, each farm was rated on four categories of conservation quality by a team of ecologists with expertise in this area: (1) total area of semi-natural habitat on the farm; (2) the number of different habitats present; (3) the number of conservation management options adopted to enhance the biodiversity of natural elements on the farm (e.g., protection from fertilizer and agro-chemical runoffs, active removal of excess nutrients, timing of management in relation to breeding season); and (4) the contribution of the habitats and specific measures beneficial to species occurrence and survival (e.g., nesting boxes for songbirds, owls and raptors, roosting facilities for bats, etc.) and the occurrence of specific groups of organisms (e.g., farmland birds, songbirds, raptors, amphibians, invertebrates, etc.). Participants' performance in each of these categories was compared with the performance of others in their area. The feedback reports presented this information in a clear and understandable way. The feedback was combined with tailored recommendations on how to improve their score in each of the four categories.

In the tailored information plus public commitment group $(N=16)$, participants were invited to a meeting - one for each agricultural organization so that all participants attended together with their fellow members. During these meetings, reports organized identically to those for the information only group were handed out and participants were given the opportunity to read their reports and discuss the contents among themselves. At the end of each meeting we asked participants to publicly state which of the recommendations given in their report they would follow up on. In order to enhance the effects of these public statements, minutes of the meeting, including every participant's commitments, were sent to all participants. Of the 16 participants in the tailored information plus public commitment group, 12 were able to attend the meetings. All the participants present at the meeting made a public commitment. Participants who did not attend the study groups were excluded from further analysis. The control group $(N=24)$ received no reports. A year later, in March 2007, all participants were sent the post-intervention questionnaire.
Questionnaire

All questionnaire responses were measured on a five-point scale. Because we were interested in the possible differences between non-subsidized and subsidized conservation, all items were phrased for both types of practices. All responses were measured before and after the intervention.

Psychological and Behavioral Measures Attitude was measured using responses to the following statements:

- I think that subsidized/ non-subsidized nature conservation practices are: negative-positive

- I think that subsidized/ non-subsidized nature conservation practices are: useless-useful

- I think that subsidized/ non-subsidized nature conservation practices are: unimportant-important (Azjen and Fishbein 1980).

This yielded a sufficiently high reliability for both subsidized $(\alpha=.77)$ and non-subsidized practices $(\alpha=.87)$ in the pre-test as well as in the post-test (subsidized $\alpha=.76$, nonsubsidized $\alpha=.91$ ). The desire to engage in nature conservation practices was assessed on the basis of responses to the statement: "I want to perform subsidized/non-subsidized nature conservation practices." According to the Model of Goal-Directed Behavior, desires "represent the motivational state of mind wherein appraisals and reasons to act are transformed into a motivation to do so" (Perugini and Bagozzi 2001, p. 84). Therefore, they can be seen as a determinant of behavior. For the current study we were particularly interested in using this variable as it reflects an individual's motivation to engage in a given behavior irrespective of possible practical barriers. Nature conservation is characterized by a number of practical barriers such as subsidies, changing regulations and income. This measure provided us with the opportunity to assess the effect of our intervention on personal motivation to engage in conservation efforts.

Area of (semi-)natural habitat was calculated from selfreported data on specific semi-natural habitats present on the farm. Also, we asked participants if they were interested in expanding their current area of subsidized (semi-)natural habitat.

Finally, we asked participants how much time they had spent on both subsidized and non-subsidized nature conservation practices per season in the past year. We then aggregated these season scores to measures indicating how much time they had spent on both subsidized and nonsubsidized conservation practices per year.

Ecological Measures Conservation quality was assessed by asking questions regarding the use of fertilizer and pesticides, mowing/cutting/vegetation removal regime and timing of 
conservation efforts in relation to breeding and overwintering periods of fauna and seeding periods of flora. These were aggregated into the following four categories to enable comparison between differently managed habitats (Van Dijk et al. 2009): (1) protection of the habitat from regular farm practice (e.g., actively avoiding fertilizer or pesticide runoffs); (2) guaranteeing spatial and/or temporal continuity of the habitat (e.g., phased mowing or replanting trees); (3) actively influencing vegetation structure (e.g., selective cutting of trees, removal of exuberant water plant growth); (4) active nutrient reduction (e.g., haymaking). If a farmer performed one or more management options within a specific category, one point for management quality was awarded. In total, a management quality score between zero (no beneficial management) and four (high management quality) could be calculated for each habitat. Overall conservation quality was defined as the average of the management scores of all seminatural habitats present at the farm.

Another ecological measure used was the diversity of habitats. A habitat is commonly defined as "a place where an organism or a biological population normally lives or occurs" (http://www.biology-online.org). Habitat diversity was defined as the total number of different habitats and was calculated from the self-reported data by adding the number of habitats reported to be present on the farm.

\section{Results}

We will first discuss the psychological and behavioral measures, after which we will turn to effects found on the ecological measures. All means and standard deviations are listed in Table 1.

One important feature of the current study is that it involves a collaboration of social psychological and ecological scientists. Using ecological measures makes it necessary to select a sample that is not affected by differences in soil or landscape. Because of these stringent criteria, our final sample was relatively small. Since this

Table 1 Means and standard deviations for all the dependent variables before and after the intervention, for every condition

\begin{tabular}{|c|c|c|c|c|c|c|c|}
\hline & & \multicolumn{2}{|l|}{ Control } & \multicolumn{2}{|c|}{ Information } & \multicolumn{2}{|c|}{ Information plus Commitmen } \\
\hline & & M & SD & M & $\mathrm{SD}$ & M & SD \\
\hline \multirow[t]{2}{*}{ Attitude subsidized } & Pretest & 3.98 & .10 & 4.19 & .11 & 3.96 & .15 \\
\hline & Posttest & 4.00 & .12 & 3.98 & .12 & 4.07 & .17 \\
\hline \multirow[t]{2}{*}{ Attitude unsubsidized } & Pretest & 3.81 & .17 & 3.84 & .18 & 3.91 & .22 \\
\hline & Posttest & 3.70 & .19 & 3.73 & .20 & 4.03 & .25 \\
\hline \multirow[t]{2}{*}{ Desire subsidized } & Pretest & 3.91 & .20 & 4.24 & .23 & 3.73 & .28 \\
\hline & Posttest & 3.86 & .18 & 4.19 & .20 & 4.27 & .25 \\
\hline \multirow[t]{2}{*}{ Desire unsubsidized } & Pretest & 3.00 & .22 & 2.53 & .26 & 2.91 & .32 \\
\hline & Posttest & 2.57 & .25 & 2.77 & .29 & 3.27 & .36 \\
\hline \multirow[t]{2}{*}{ Time spent subsidized (hours) } & Pretest & 34.90 & 8.49 & 37.33 & 8.95 & 27.65 & 12.01 \\
\hline & Posttest & 34.40 & 6.83 & 37.44 & 7.20 & 38.40 & 9.66 \\
\hline \multirow[t]{2}{*}{ Time spent unsubsidized (hours) } & Pretest & 113.33 & 22.45 & 58.33 & 26.56 & 22.30 & 32.53 \\
\hline & Posttest & 48.52 & 12.02 & 37.93 & 14.22 & 73.25 & 17.42 \\
\hline \multirow[t]{2}{*}{ Wish to expand } & Pretest & 3.86 & .21 & 3.72 & .23 & 3.36 & .30 \\
\hline & Posttest & 3.46 & .22 & 3.17 & .25 & 3.27 & .31 \\
\hline \multirow[t]{2}{*}{ Surface area subsidized (ha) } & Pretest & 2.51 & .50 & 2.21 & .54 & 2.29 & .79 \\
\hline & Posttest & 2.71 & .54 & 2.88 & .58 & 2.47 & .85 \\
\hline \multirow[t]{2}{*}{ Surface area not subsidized (ha) } & Pretest & .59 & .17 & .71 & .19 & .47 & .24 \\
\hline & Posttest & .69 & .18 & .81 & .20 & .90 & .25 \\
\hline \multirow[t]{2}{*}{ Quality subsidized conservation } & Pretest & 1.71 & .21 & 2.01 & .23 & 1.89 & .30 \\
\hline & Posttest & 1.85 & .19 & 2.29 & .21 & 2.51 & .27 \\
\hline \multirow[t]{2}{*}{ Quality unsubsidized conservation } & Pretest & 1.97 & .25 & 1.96 & .27 & 2.20 & .39 \\
\hline & Posttest & 2.04 & .26 & 1.94 & .28 & 2.24 & .41 \\
\hline \multirow[t]{2}{*}{ Habitat diversity subsidized } & Pretest & 1.52 & .27 & 2.41 & .29 & 3.18 & .41 \\
\hline & Posttest & 1.64 & .35 & 2.86 & .37 & 3.36 & .53 \\
\hline \multirow[t]{2}{*}{ Habitat diversity not subsidized } & Pretest & 4.20 & .54 & 4.32 & .58 & 3.55 & .82 \\
\hline & Posttest & 5.08 & .59 & 5.53 & .63 & 4.73 & .89 \\
\hline
\end{tabular}


study is, to the best of our knowledge, the first to test the effects of a social psychological intervention on nature conservation practiced by farmers, it is exploratory in nature. Therefore, we believe the need to reveal possible effects to be greater than the risk of false positive decisions (Myers 1972; see also Hartig et al. 1991). We thus also report effects at the $p<.10$ level.

\section{Psychological and Behavioral Measures}

Attitude A repeated measure analysis of variance on attitude towards conservation was performed. Subsidy (subsidized versus non-subsidized) and time (before and after the intervention) were used as the within-subjects factors and experimental condition as the between-subjects factor. This analysis showed a significant main effect of subsidy, $F(1,40)=4.56, p=.04$. Attitude towards subsidized conservation was more positive $(M=4.02)$ than attitude towards non-subsidized conservation $(M=3.81)$. There were no effects of our intervention.

\section{Desire to Engage in Nature Conservation Efforts Repeated} measure analysis of variance on desire to engage in conservation with time and subsidy as the within-subjects factors and experimental condition as the between-subjects factor showed a significant main effect of subsidy, $F(1,46)=$ $54.77, p=.00$. The desire to engage in subsidized conservation was stronger $(M=4.00)$ than the desire to engage in non-subsidized conservation $(M=2.80)$. This analysis also showed a significant interaction effect of time*experimental condition, $F(2,46)=3.491, p=.04$. The average score of behavioral desire did not change significantly in the control condition (from $M=3.43$ to $M=3.16, p=.16$ ) nor in the tailored information only condition (from $M=3.34$ to $M=3.38, p=.79$ ). It did, however, increase significantly in the tailored information plus public commitment condition (from $M=3.32$ to $M=3.77, p=.05$, one-sided). These results are in line with our hypothesis that the combination of tailored information and public commitment in particular would result in a higher willingness to engage in conservation.

Area of (Semi-)natural Habitat A repeated measure analysis of variance on the surface area of natural habitat with time and subsidy as the within-subjects factors and experimental condition as the between-subjects factor was performed. This analysis showed a significant main effect of subsidy, $F(1,39)=28.15, p=.00$. Our participants had more subsidized $(M=2.60 \mathrm{ha})$ than non-subsidized $(M=.64 \mathrm{ha})$ surface area of natural habitat. This analysis also showed a significant main effect of time $F(1,39)=7.88, p=.01$, showing that that the area of natural habitat increased across all conditions (from $M=1.47$ ha to $M=1.77 \mathrm{ha}$ ).
The three-way interaction of time*subsidy*condition was not significant overall, $F(2,39)=1.99, p=.15$. However, given our specific hypothesis that especially the combination of tailored information and public commitment would affect area of natural habitat, we looked at subsidized and non-subsidized conservation separately. A repeated measure analysis of variance on the area of subsidized natural habitat with time as the within-subjects factor and experimental condition as the between-subjects factor showed no significant interaction of time*experimental condition, $F(2,42)=0.95, n s$. However, a similar analysis on the area of non-subsidized natural habitat did show an interaction of time*experimental condition, $F(2,48)=2.89, p=.07$. Repeated measures analysis per condition showed that the largest change occurred in the tailored information plus public commitment condition, where participants increased their area of non-subsidized natural habitat from 0.47 to 0.90 ha, $p=.06$, one-sided. This confirms our hypothesis that the combination of tailored information and public commitment would be particularly successful in increasing conservation.

We also asked participants if they were interested in expanding their current area of subsidized (semi-) natural habitat. A repeated measure analysis of variance with time as the within-subjects factor and experimental condition as the between-subjects factor was performed. Results showed a significant main effect of time, $F(1,49)=8.15, p=.01$. The wish to expand decreased across all conditions. We expected this decrease to be caused by participants who had already expanded their area of subsidized natural habitat. Therefore, we calculated the difference scores of area of subsidized natural habitat by subtracting the area of subsidized natural habitat in 2006 from the area of subsidized natural habitat in 2007 . We then included this difference score in the analysis as a covariate and indeed the effect of time disappeared $F(1,40)=2.26$, ns. This suggests that our finding that the wish to expand decreased across all conditions is explained by the fact that farmers had in the meantime expanded their area of subsidized natural habitat.

Time Spent on Conservation A repeated measure analysis of variance on time spent on conservation with time and subsidy as the within-subjects factors and experimental condition as the between-subjects factor showed a significant main effect of subsidy, $F(1,42)=7.49, p=.01$. Participants reported spending less time on subsidized $(M=$ $34.64 \mathrm{~h})$ than on non-subsidized conservation $(M=55.26 \mathrm{~h})$. This analysis also showed a significant interaction of time*experimental condition, $F(2,42)=4.22, p=.02$. The amount of time spent on conservation decreased in the control condition (from $M=67.95$ to $M=34.83, p=.02$ ) as well as in the tailored information only condition (from $M=$ 
49.37 to $M=36.77, p=.27$ ). It did, however, increase in the tailored information plus public commitment condition (from $M=24.98$ to $M=55.83, p=.10$, one-sided). This analysis also showed a significant three-way interaction of time*subsidy*experimental condition, $F(2,42)=4.97$, $p=.01$. To explore the nature of this interaction we looked at subsidized and non-subsidized conservation separately. A repeated measure analysis of variance on time spent on subsidized practices with time as the within-subjects factor and experimental condition as the between-subjects factor showed no significant interaction of time*experimental condition, $F(2,45)=0.57, p=.57$. However, a similar analysis on time spent on non-subsidized practices did show a significant interaction of time*experimental condition, $F(2,46)=4.56, p=.02$. Repeated measures analysis per condition showed that the time spent on non-subsidized practices decreased in the control condition from $M=111.59$ to $M=46.32(p=.01)$. The time spent on non-subsidized practices in the tailored information only condition decreased as well (from $M=58.33$ to $M=37.93, p=.33$ ). It did, however, increase in the tailored information plus public commitment condition (from $M=22.30$ to $M=73.25, p=.06$, one-sided). This analysis shows that during the course of our intervention, participants in the tailored information plus public commitment condition had spent more time on conservation, and that this was especially true for nonsubsidized conservation. Because of the large differences in time spent on conservation between conditions before our intervention, these results must be interpreted with caution. However, they are in line with our hypothesis.

\section{Ecological Measures}

Conservation Quality Next, we looked at the quality of conservation. A repeated measure analysis of variance on quality of conservation practices and time and subsidy as the within-subjects factors and experimental condition as the between-subjects factor showed a significant main effect of time, $F(1,35)=5.56, p=.03$. Quality of conservation practices increased across all conditions, from $M=2.04$ to $M=2.20$. The interaction of time*subsidy was also significant $F(1,35)=3.29, p=.04$, one-sided. The quality of subsidized conservation practices increased over time $(M=$ 1.89 to $M=2.22, p=.00$ ) whereas the quality of nonsubsidized conservation practices $\operatorname{did}$ not $(M=1.93$ to $M=$ 2.01, ns.). In other words, the main effect of time was qualified by the interaction effect of time*subsidy. This increase in quality of conservation was not due to our intervention.

Habitat Diversity We also looked at the diversity of habitats per farm. A repeated measure analysis of variance with habitat diversity before and after the intervention and subsidy as the within-subjects factors and experimental condition as the between-subjects factor showed a significant main effect of subsidy, $F(1,56)=20.87, p=.00$. Habitat diversity was lower $(M=2.58)$ for subsidized conservation than for non-subsidized conservation $(M=4.54)$. This means that non-subsidized (semi-) natural habitat was more diverse than subsidized (semi-) natural habitat. The analysis also showed a significant main effect of time, $F(1,56)=$ $56.08, p=.00$. Habitat diversity increased across all conditions, from $M=3.24$ to $M=3.88$. The interaction of time*subsidy was also significant $F(1,56)=25.52, p=.00$ : non-subsidized habitat diversity increased more strongly ( $M=4.02$ to $M=5.05, p=.00$ ) over time than subsidized habitat diversity $(M=2.45$ to $M=2.70, p=.00)$. Nonsubsidized habitat diversity was not only higher to begin with, but also increased more than subsidized diversity during the course of our intervention. Since there were no significant differences between experimental conditions, this increase cannot be attributed to our intervention.

\section{General Discussion}

By adopting conservation practices, farmers can strongly affect environmental quality and biodiversity. In this paper we have seen that an intervention strategy containing tailored information and public commitment making can improve conservation practices. Our results show that the combination of tailored information and the making of public commitments was especially effective in eliciting behavior change: participants showed a stronger desire to engage in conservation, increased their area of nonsubsidized natural habitat, and reported spending more time on non-subsidized conservation. Participants in the tailored information only condition also increased their area of non-subsidized natural habitat but did not show any change on other measures. In addition, we found that while our intervention affected both types of conservation, the effects were stronger for non-subsidized conservation.

We found some other noteworthy differences between subsidized and non-subsidized conservation. Attitudes towards subsidized conservation were more positive than towards non-subsidized conservation. This difference can be explained in terms of Azjen's (1991) Theory of Planned Behavior, according to which the monetary reward for behavior increases the positive attitude towards that behavior. The fact that the desire to engage in subsidized conservation was also stronger than the desire to engage in non-subsidized conservation should be seen from the same perspective. However, the desire to engage in non-subsidized conservation proved sensitive to our intervention. 
The quality of subsidized conservation practices increased over time whereas the quality of non-subsidized conservation practices did not. However, non-subsidized conservation was characterized by higher habitat diversity than subsidized conservation. These findings are hard to explain from the current data. It could be that farmers have more knowledge of subsidized conservation practices and are therefore better able to improve the quality of this type of conservation. As for habitat diversity, it could be that since non-subsidized conservation is not contingent on contracts and thus more flexible, it gives farmers greater freedom in choosing how to pursue conservation, which might then result in higher habitat diversity.

The effects of our intervention show that the combination of tailored information and public commitment increases the desire to engage in conservation, time spent on non-subsidized conservation and area of non-subsidized (semi-)natural habitat. The results presented here are particularly impressive when we take into account that participants were asked to attend only one meeting during the course of the intervention at which they made a public commitment to pursue conservation practices. Our public commitment manipulation did not affect all the dependent measures in our study - attitude, quality of conservation and habitat diversity did not change. That attitude did not change might be due to the fact that participants publicly committed themselves only once. As for quality of conservation and habitat diversity, these are ecological measures that might very well be too multi-determined to change within a year.

Another reason why we believe our results to be very promising is that research has shown that farmers' attitudes and involvement concerning biodiversity are very resistant to change. In fact, several studies have shown that conservation practices themselves do not influence farmers' attitudes and behavior (Burton et al. 2008). Research by Herzon and Mikk (2007) showed that in Estonia, 12 years of subsidizing agricultural-environmental measures did not increase farmers' understanding of biodiversity, nor of how to improve it. Although our intervention was not successful in eliciting attitude change, it did prompt farmers to expand their area of non-subsidized (semi-)natural habitat, and to devote more time to conservation.

It is important to note that our intervention lasted only one year. Considering the often complex decision making required of farmers and the fact that subsidized conservation is contingent on contracts of multiple years, it seems reasonable to assume that had we been able to continue the intervention for a longer period of time, we would have found more and/or stronger effects.

For this study we recruited participants who were members of local agricultural organizations. While we have no specific information about our participants' degree of involvement with these organizations, it is very plausible that those farmers who signed up for our study are in fact the more active members. This means that they constitute a group of early adapters in terms of their engagement with nature conservation. On the one hand, one might consider this a limitation of the study. On the other hand, we believe that it makes sense that an intervention such as ours that is completely based on voluntary behavior change, is most likely to reach those people who are already somewhat involved in the issue at hand. These early adapters can in turn influence those members that are less engaged, eventually contributing to the intervention's success.

One aspect of non-subsidized nature conservation that was not included in this study was the cost of that conservation. Farmers have a wide array of possible nonsubsidized conservation behaviors and it is very likely that these behaviors differ in terms of costs. Some behaviors may be easier to perform than others, while others may require a financial investment. The farmers in our sample engaged in different conservation behaviors. Due to our relatively small sample, it was not possible to compare different conservation behaviors in terms of financial, behavioral or psychological costs. It is of course likely that farmers will most often choose the conservation behavior that to them is less costly. Following this line of reasoning, it seems plausible that an intervention that targets these behaviors would yield the best results. We recommend that future research in this area includes the cost factor.

The current study is, to the best of our knowledge, the first to test the effects of a social psychological intervention on nature conservation practiced by farmers, and is therefore exploratory in nature. Current knowledge about the social psychological underpinnings of farmers' conservation is limited (Burton and Wilson 2006; Lokhorst et al. 2009a). In fact, we do not know of any study involving farmers that has used a quasi-experimental design to test causal effects of interventions on conservation. Because of this exploratory nature and our relatively small sample size, we have chosen to include effects that were significant at the $p<.10$ level. Another issue to consider is that our conditions differed in initial mean scores on some variables. These differences are mainly due to measures of non-subsidized conservation that are characterized by a high variability (see also Table 1).

Another issue that needs to be addressed is that our results were based on self-reported data. A critic might argue that the effects we found may have been caused by participants being eager to show follow-up on their previous publicly-made commitments without actually changing their behavior. Of course, measuring actual changes in behavior would have improved our study and results. However, several studies have shown that the making of commitments affects environmental behaviors 
(DeLeon and Fuqua 1995; Katzev and Pardini 1987-88; Wang and Katzev 1990). Also, work by Kerr et al. (1997) showed that participants followed up on public commitments whether they were being monitored by others or not, ruling out the possibility that people adhere to public commitments in order to be seen as consistent by others. Taken together, we believe our results are an important first step in developing ways to improve agricultural nature conservation, and we hope this first attempt at improving farmers' conservation practices can serve as an impetus for future research in this area.

In conclusion, this research has shown that a relatively straightforward intervention can significantly improve agricultural nature conservation. The intervention we tested can be used by policymakers: the administration of feedback and tailored recommendations is not hard to implement when there are appropriate data. Public commitment initiatives could be implemented by working together with local farmers' organizations to ensure commitments are made within a group of peers. Given the promising effects of the current study, such initiatives are likely to positively affect farmers' conservation practices and environmental quality in general.

Acknowledgement This research was supported by the Netherlands Organization for Scientific Research (NWO), grant number 474-03-385.

Open Access This article is distributed under the terms of the Creative Commons Attribution Noncommercial License which permits any noncommercial use, distribution, and reproduction in any medium, provided the original author(s) and source are credited.

\section{References}

Abrahamse, W., Steg, L., Vlek, C., and Rothengatter, T. (2005). A Review of Intervention Studies Aimed at Household Energy Conservation. Journal of Environmental Psychology 25: 273-291.

Abrahamse, W., Steg, L., Vlek, C., and Rothengatter, T. (2007). The Effect of Tailored Information, Goal Setting, and Tailored Feedback on Household Energy Use, Energy-Related Behaviors, and Behavioral Antecedents. Journal of Environmental Psychology 27: $265-276$

Ajzen, I. (1991). The Theory of Planned Behavior. Organizational Behavior and Human Decision Processes 50: 179-211.

Ajzen, I., and Fishbein, M. (1980). Understanding Attitudes and Predicting Social Behaviour.. Prentice-Hall, Englewood Cliffs.

Benton, T. G., Vickery, J. A., and Wilson, J. D. (2003). Farmland Biodiversity: Is Habitat Heterogeneity the Key? Trends in Ecology and Evolution 18: 182-188.

Berendse, F., Chamberlain, D., Kleijn, D., and Schekkerman, H. (2004). Declining Biodiversity in Agricultural Landscapes and the Effectiveness of Agri-Environment Schemes. Ambio 33: 499-502.

Blomqvist, M. M., Tamis, W. L. M., Bakker, J. P., and van der Meijden, E. (2006). Seed and (micro)Site Limitation in Ditch Banks: Germination, Establishment and Survival Under Different
Management Regimes. Journal of Nature Conservation 14: 1633.

Burton, R. J. F., and Wilson, G. A. (2006). Injecting Social Psychology Theory Into Conceptualisations of Agricultural Agency: Towards a Post-Productivist Farmer Self-Identity? Journal of Rural Studies 22: 95-115.

Burton, R. J. F., Kuczera, C., and Schwarz, G. (2008). Exploring Farmers' Cultural Resistance to Voluntary Agri-Environmental Schemes. Sociologia Ruralis 48: 16-37.

Daamen, D. D. L., Staats, H., Wilke, H. A. M., and Engelen, M. (2001). Improving Environmental Behavior in Companies. The Effectiveness of Tailored Versus Non-Tailored Interventions. Environment and Behavior 33: 229-248.

DeLeon, I. G., and Fuqua, R. W. (1995). The Effects of Public Commitment and Group Feedback on Curbside Recycling. Environment and Behavior 27: 233-250.

De Young, R. (1993). Changing Behavior and Making it Stick. The Conceptualization and Management of Conservation Behavior. Environment and Behavior 25: 185-205.

Duelli, P. (1997). Biodiversity Evaluation in Agricultural Landscapes: An Approach at Two Different Scales. Agriculture, Ecosystems \& Environment 62: 81-91.

Dwyer, W. O., Leeming, F. C., Cobern, M. K., Porter, B. E., and Jackson, J. M. (1993). Critical Review of Behavioral Interventions to Preserve the Environment: Research Since 1980. Environment and Behavior 25: 275-321.

European Commission, Directorate-General for agriculture (2003). Agriculture and the Environment. Retrieved November 26, 2008, from http://ec.europa.eu/agriculture/envir/index_en.htm.

Frey, B. S. (1997). On the Relationship Between Intrinsic and Extrinsic Work Motivation. International Journal of Industrial Organization 15: 427-439.

Gardner, G. T., and Stern, P. C. (2002). Environmental Problems and Human Behavior, 2nd edn., Pearson Custom Publishing, Boston.

Harland, P., Staats, H., and Wilke, H. A. M. (1999). Explaining ProEnvironmental Intention and Behavior by Personal Norms and the Theory of Planned Behavior. Journal of Applied Social Psychology 29: 2505-2528.

Hartig, T., Mang, M., and Evans, G. (1991). Restorative Effects of Natural Environment Experiences. Environment and Behavior 23: 3-26.

Herzon, I., and Mikk, M. (2007). Farmers' Perceptions of Biodiversity and Their Willingness to Enhance it Through Agri-Environment Schemes: A Comparative Study from Estonia and Finland. Journal for Nature Conservation 15: 10-25.

Katzev, R. D., and Johnson, T. R. (1983). A Social-Psychological Analysis of Energy Consumption: The Impact of Minimal Justification Techniques. Journal of Economic Psychology 3: 267-284.

Katzev, R. D., and Pardini, A. (1987-88). The comparative effectiveness of reward and commitment in motivating community recycling. Journal of Environmental Systems 17:93-113.

Katzev, R. D., and Wang, T. (1994). Can Commitment Change Behavior? A Case Study of Environmental Actions. Journal of Social Behavior and Personality 9: 13-26.

Kerr, N. L., Garst, J., Lewandowski, D. A., and Harris, S. E. (1997). That Still, Small Voice: Commitment to Cooperate as An Internalized vs. A Social Norm. Personality and Social Psychology Bulletin 23: 1300-1311.

Kleijn, D., and Sutherland, W. J. (2003). How Effective are European Agri-Environment Schemes in Conserving and Promoting Biodiversity? Journal of Applied Ecology 40: 947-969.

Lokhorst et al. (2009a). What's in it for me? A social-cognitive explanation of motivational differences between farmers' voluntary and subsidized nature conservation practices. (submitted for publication). 
Lokhorst et al. (2009b). A review of commitment making strategies in environmental research. (submitted for publication).

Manhoudt, A. G. E., Visser, A. J., and De Snoo, G. R. (2007). Management Regimes and Farming Practices Enhancing Plant Species Richness on Ditch Banks. Agriculture, Ecosystems \& Environment 119: 353-358.

Matthies, E., Klockner, C. A., and Preissner, C. L. (2006). Applying a Modified Moral Decision Making Model to Change Habitual Car Use: How Can Commitment be Effective? Applied Psychology - An International Review 55: 91-106.

Myers, J. L. (1972). Fundamentals of Experimental Design, 2nd edn., Allyn \& Bacon, Boston.

Oerlemans, N., Guldemond, J. A., and Visser, A. (2007). Meerwaarde Agrarische Natuurverenigingen Voor De Ecologische Effectiviteit Van Programma Beheer: Ecologische Effectiviteit Regelingen Natuurbeheer. [Added value of Agricultural organizations for the ecological effectivity of Programma Beheer]. Retrieved June 12th, 2008, from library.wur.nl.

Pallak, M., and Cummings, N. (1976). Commitment and Voluntary Energy Conservation. Personality and Social Psychology Bulletin 2: 27-31.

Perugini, M., and Bagozzi, R. P. (2001). The Role of Desires and Anticipated Emotions in Goal-Directed Behaviours: Broadening and Deepening the Theory of Planned Behaviour. British Journal of Social Psychology 40: 79-98.

Petty, R. E., and Cacioppo, J. T. (1986). Communication and Persuasion: Central and Peripheral Routes to Attitude Change. Springer, New York.
Staats, H., Van Leeuwen, E., and Wit, A. (2000). A Longitudinal Study of Informational Interventions to Save Energy in a Office Building. Journal of Applied Behavior Analysis 33: 101-104.

Staats, H., Harland, P., and Wilke, H. A. M. (2004). Effecting Durable Change: A Team Approach to Improve Environmental Behavior in the Household. Environment and Behavior 36: 341-367.

Stern, P. C., and Oskamp, S. (1987). Managing scarce environmental resources. In Stokols, D., and Altman, I. (eds.), Handbook of Environmental Psychology. Wiley, New York, pp. 1043-1088.

Van Dijk, J., Lokhorst, A. M., Staats, H., and De Snoo, G. (2009). No Pay, No Cure? Subsidized and Voluntary Agri-Environmental Management on Arable Farms. Manuscript in preparation.

Van Paassen, A., and Schrieken, N. (1998). Handbook for AgriEnvironmental Management. Landschapsbeheer Nederland, Utrecht, The Netherlands [in Dutch].

Wang, T. E., and Katzev, R. D. (1990). Group Commitment and Resource Conservation: Two Field Experiments on Promoting Recycling. Journal of Applied Social Psychology 20: 265275.

Weibull, A. C., Ostman, O., and Granqvist, A. (2003). Species Richness in Agroecosystems: The Effect of Landscape, Habitat and Farm Management. Biodiversity Conservation 12: 1335-1355.

Werner, C. M., Turner, J., Shipman, K., Twitchell, S. F., Dickson, B. R., Bruschke, G. V., and von Bismarck, W. B. (1995). Commitment, Behavior, and Attitude Change: An Analysis of Voluntary Recycling. Journal of Environmental Psychology 15: 197-208. 